\title{
Defuzzification Formula for Modelling and Scheduling A Furniture Fuzzy Project Network
}

\author{
S. Maheswari, M. Shalini, T. L. Yookesh
}

\begin{abstract}
This research article presents a new defuzzification formula for deciding the critical path in a proposed network. Here we introduce an octagonal fuzzy numbers for representing the duration time. It is shown that it is better to use octagonal fuzzy numbers towards determining the critical path. A numerical example is given and the proposed formula as compared with the existing fuzzy numbers.
\end{abstract}

Keywords: FCPM, fuzzy project network, fuzzy numbers, defuzzification.

MSC: 63E72, 65K10, 90B15.

\section{INTRODUCTION}

The critical path method (CPM), worked out toward the start of the 1960s, Starting with the second part of the 1970 s proposed in $[5,8,11]$. In [10] they calculated the critical path by considering the needed sources, the time of project completion. Zadeh [12] introduced an another path to accord with vague data is to use the perception of fuzziness. Jain [4] proposed the idea of fuzzy numbers and positioning fuzzy numbers. In [1] acquainted a calculation with carryout critical path under fuzzy domain. In [3] they computed fuzzy math operations to calculate the fuzzy earliest starting time of activity in a network.

In [2] concentrated on the choice of the centroid strategy to find crisp values which speak to uncertain information. In [9] developed a proposed centroid method for trapezoidal fuzzy number. In [7] displayed an arranging model for a helicopter support focus, it is to ensure a decent administration level to restrict flying machine visit length. In [6] presented a wellbeing related personal satisfaction by utilizing four-advance calculation of positioning fuzzy numbers.

This paper, we present an approach, which is not researched so far. We used octagonal fuzzy numbers for centroid method to find the critical path. We compared our proposed fuzzy number with the existing triangular and trapezoidal fuzzy numbers. The conclusion has arrived through numerical example.

\section{Revised Manuscript Received on December 15, 2019.}

S. Maheswari, Department of Mathematics, M.Kumarasamy College of Engineering, Karur- Tamil Nadu, India. Email smaheswari28@gmail.com

M. Shalini, S. Maheswari, Department of Mathematics, M.Kumarasamy College of Engineering, Karur- Tamil Nadu, India. Email: drshalinimath@gmail.com

T. L. Yookesh, Department of Science and Humanities, VFSTR (Deemed to be University), Guntur-(A.P.) India. Email:, renu_yookesh@yahoo.co.in

\section{PRELIMINARIES}

Here, we present the most basic concepts and defuzzification.

\subsection{Fuzzy set}

If $\mathrm{X}$ is a collection of objects denoted generically byx,then a fuzzy setAin $\mathrm{X}$ is a set of ordered pair $A=\left\{\left(x, \mu_{A}(x): x \in X\right)\right\}$ where $\mu_{A}(\mathrm{x})$ is called themembership function of $A$.

\subsection{Fuzzy number}

The fuzzy number A is a fuzzy set of the real number $\mathrm{R}$ with membership function

$\mu_{A}(x)$ satisfies

$$
\begin{aligned}
& \text { 1. } \mu_{A}(x) \text { is continuous } \\
& \text { 2. } \mu_{A}(x) \text { is increasing }
\end{aligned}
$$

in $(a, b)$

in $(\mathrm{c}, \mathrm{d})$.

$$
\text { 3. } \mu_{A}(x) \text { is decreasing }
$$

\subsection{Trapezoidal fuzzynumber}

$\mu_{A}(x)=\left\{\begin{array}{cc}\frac{x-b 1}{b 2-b 1}, & b 1 \leq x \leq b 2 \\ 1, & b 2 \leq x \leq b 3 \\ \frac{x-b 4}{b 3-b 4}, & b 3 \leq x \leq b 4 \\ 0, & \text { otherwise }\end{array}\right.$

Here $A=(b 1, b 2, b 3, b 4)$ is a trapezoidal fuzzy number

\subsection{Triangular fuzzy number}

$\mu_{A}(x)=\left\{\begin{array}{cl}\frac{x-b 1}{b 2-b 1}, & b 1 \leq x \leq b 2 \\ \frac{x-b 3}{b 2-b 3}, & b 2 \leq x \leq b 3 \\ 0, & \text { otherwise }\end{array}\right.$

Here $A=(b 1, b 2, b 3)$ is a triangular fuzzy number

\subsection{Defuzzification}

Transformation from a fuzzy set to a crisp number is called a defuzzification. defuzzification is required when you want a crisp number as output from a fuzzy system. It can take many forms, but the most standard defuzzification is through computing the centroid method. 


\section{Defuzzification Formula for Modelling and Scheduling A Furniture Fuzzy Project Network}

\subsection{Arithmeticoperations}

Give $\mathrm{A}$ and $\mathrm{B}$ be two
octagonal fuzzy numbers
parameterized

$\operatorname{by}(A 1, \mathrm{~A} 2, \mathrm{~A} 3, \mathrm{~A} 4, \mathrm{~A} 5, \mathrm{~A} 6, \mathrm{~A} 7, A 8)$ and

(B1,B 2, B 3, B 4, B 5, B 6, B 7, B 8) respectively. The simplified fuzzynumber arithmetic operations between the fuzzy numbers Aand Bare as follows: Fuzzy numbers addition $\oplus$ :

$$
\begin{aligned}
& (\mathrm{A} 1, \mathrm{~A} 2, \mathrm{~A} 3, \mathrm{~A} 4, \mathrm{~A} 5, \mathrm{~A} 6, \mathrm{~A} 7, A 8) \oplus(\mathrm{B} 1, \mathrm{~B} 2, \mathrm{~B} 3, \mathrm{~B} 4, \mathrm{~B} \\
& 5, \mathrm{~B} 6, \mathrm{~B} 7, \mathrm{~B} 8) \\
& =(A 1+\mathrm{B} 1, \mathrm{~A} 2+\mathrm{B} 2, \mathrm{~A} 3+\mathrm{B} 3, \mathrm{~A} 4+\mathrm{B} 4, \mathrm{~A} 5+\mathrm{B} 5, \mathrm{~A} 6+\mathrm{B} 6, \mathrm{~A} \\
& 7+\mathrm{B} 7, \mathrm{~A} 8+\mathrm{B} 8)
\end{aligned}
$$

Fuzzy numbers subtraction $\Theta$ :
(A 1,A 2,A 3, A 4, A 5, A 6, A 7,A8) $\Theta(B 1, \mathrm{~B} 2, \mathrm{~B} 3, \mathrm{~B} 4, \mathrm{~B}$ $5, \mathrm{~B} 6, \mathrm{~B} 7, \mathrm{~B} 8)$

$=(A 1-\mathrm{B} 8, \mathrm{~A} 2-\mathrm{B} 7, \mathrm{~A} 3-\mathrm{B} 6, \mathrm{~A} 4-\mathrm{B} 5, \mathrm{~A} 5-\mathrm{B} 4, \mathrm{~A} 6-\mathrm{B} 3, \mathrm{~A} 7-\mathrm{B} 2, \mathrm{~A}$ $8-B I)$

\section{PROPOSED METHOD FOR DEFUZZIFICATION}

Here, we proposed a defuzzification formula. Authors had researched on ranking methods using fuzzy numbers. And octagonal fuzzy numbers are used to find fuzzy critical path based on defuzzification method which is not researched so far. Motivation behind this study is to find a new formula to calculate fuzzy critical path precisely. Here (a,b,c,d,e,f,g,h) are octagonal fuzzy number, real numbers and its membership functions are as follows.

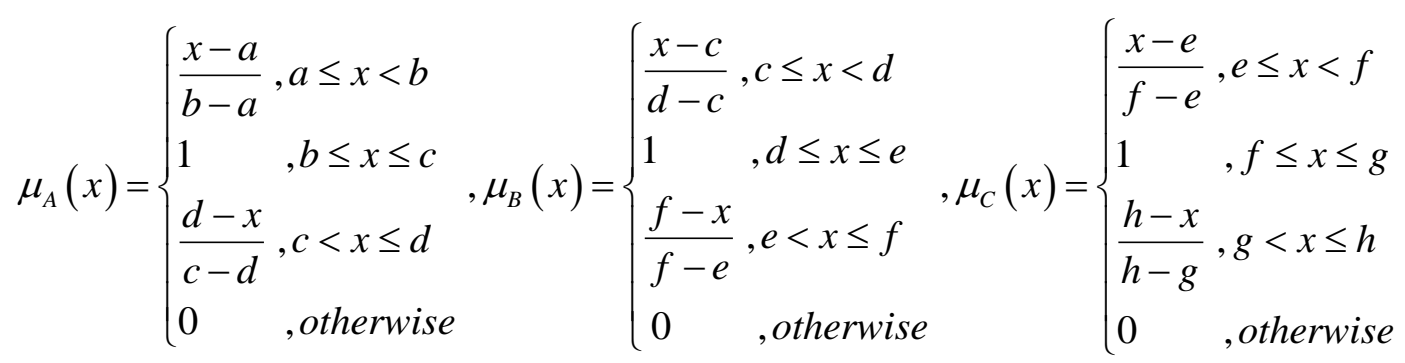

$\mu_{A}(X)$

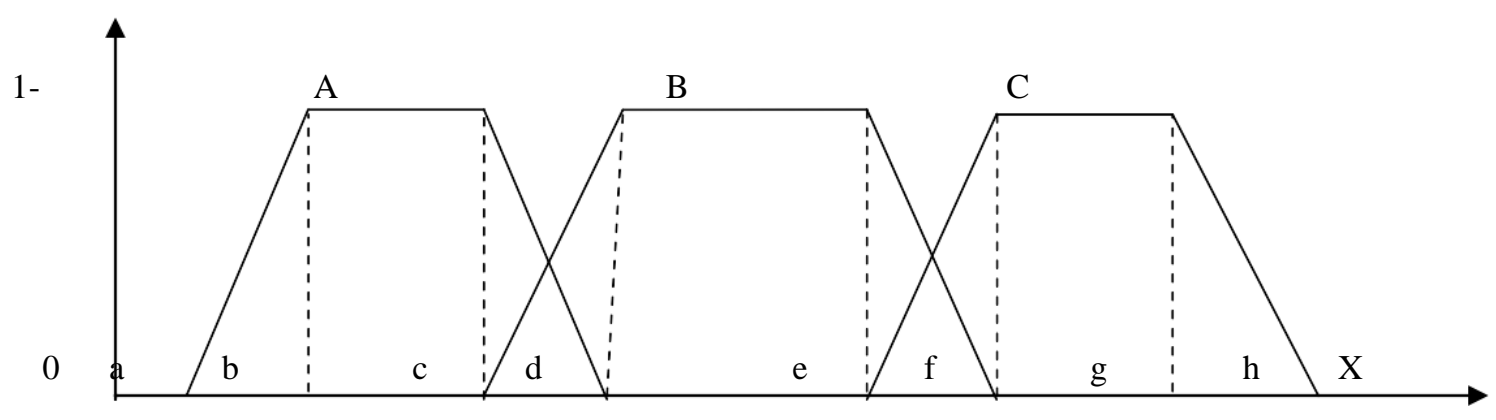

Figure 1. Representation of an octagonal fuzzy number

By fig.(1) and from the above membership function we may write the defuzzification formula as $\operatorname{Centroid}(A)=\frac{\int_{a}^{b} \frac{x-a}{b-a} x d x+\int_{b}^{c} x d x+\int_{c}^{d} \frac{d-x}{d-c} x d x+\int_{c}^{d} \frac{x-c}{d-c} x d x+\int_{d}^{e} x d x+\int_{e}^{f} \frac{f-x}{f-e} x d x+\int_{e}^{f} \frac{x-e}{f-e} x d x+\int_{f}^{g} x d x+\int_{g}^{h} \frac{h-x}{h-g} x d x}{\int_{a}^{b} \frac{x-a}{b-a} d x+\int_{b}^{c} d x+\int_{c}^{d} \frac{d-x}{d-c} d x+\int_{c}^{d} \frac{x-c}{d-c} d x+\int_{d}^{e} d x+\int_{e}^{f} \frac{f-x}{f-e} d x+\int_{e}^{f} \frac{x-e}{f-e} d x+\int_{f}^{b} d x+\int_{g}^{h} \frac{h-x}{h-g} d x}$

\subsection{Fuzzy Critical Path Algorithm}

Consider the project network, here octagonal fuzzy numbers are utilized to speak to the movement time.

$$
\begin{array}{lll}
\text { Step } \quad \text { 1: } \quad \text { Compute } E_{i}^{s} \text { 's } \quad \text { and } & E_{i}^{f} \text { 's } \\
\text { using } E_{i}^{s}= & \operatorname{Max}_{j \in P(i)}\left\{E_{j}^{s} \oplus \tilde{t}_{j}\right\} \text { and } E_{i}^{f}=E_{i}^{s} \oplus \tilde{t}_{i} & \\
\text { Step } \quad \text { 2: } \quad \text { Compute } L_{i}^{f} \text { 's } \quad \text { and } & L_{i}^{s} \text { 's } \\
\text { using } L_{i}^{f}=\operatorname{Min}_{j \in P(i)}\left\{L_{j}^{f} \Theta \tilde{t}_{j}\right\} \text { and } L_{i}^{s}=L_{i}^{f} \Theta \tilde{t}_{i} &
\end{array}
$$

Step 3: Compute $T_{i}^{F}$ 's for all the activities (i,j) using $T_{i}^{F}=L_{i}^{s} \Theta E_{i}^{s}$ or $T_{i}^{F}=L_{i}^{f} \Theta E_{i}^{f}$

Step 4: Compute the total fuzzy slack time for every path.

Step 5: The path which is having minimum value is the critical path. 


\section{PROPOSED CENTROID METHOD USING OCTAGONAL FUZZY NUMBERS}

Let $A=(a, b, c, d, e, f, g, h)$ be an octagonal fuzzy number. From fig. (1) and the above membership function the formula

is

$$
\operatorname{Centroid}(A)=\frac{\int_{a}^{b} \frac{x-a}{b-a} x d x+\int_{b}^{c} x d x+\int_{c}^{d} \frac{d-x}{d-c} x d x+\int_{c}^{d} \frac{x-c}{d-c} x d x+\int_{d}^{e} x d x+\int_{e}^{f} \frac{f-x}{f-e} x d x+\int_{e}^{f} \frac{x-e}{f-e} x d x+\int_{f}^{g} x d x+\int_{g}^{h} \frac{h-x}{h-g} x d x}{\int_{a}^{b} \frac{x-a}{b-a} d x+\int_{b}^{c} d x+\int_{c}^{d} \frac{d-x}{d-c} d x+\int_{c}^{d} \frac{x-c}{d-c} d x+\int_{d}^{e} d x+\int_{e}^{f} \frac{f-x}{f-e} d x+\int_{e}^{f} \frac{x-e}{f-e} d x+\int_{f}^{g} d x+\int_{g}^{h} \frac{h-x}{h-g} d x}
$$

By solving the above centroid equation, we get the centroid octagonal formula as given in the following equation (1).

$\operatorname{Centroid}(A)=\frac{\left(c^{2}+d^{2}+e^{2}+f^{2}+g^{2}+h^{2}+c d+e f+g h\right)-\left(a^{2}+b^{2}+c^{2}+d^{2}+e^{2}+f^{2}+a b+c d+e h\right)}{3[(c+d+e+f+g+h)-(a+b+c+d+e+h)]}$

\section{EXPERIMENTS AND RESULTS DESCRIPTION}

To delineate the proposed formula, consider the accompanying framework graph.Node.1-Wooden arms and legs, Node.2-
Wooden back, Node.3-Wooden base, Node.4foam for back and base, Node.5- Fit covers, Node.6- Set everything together.

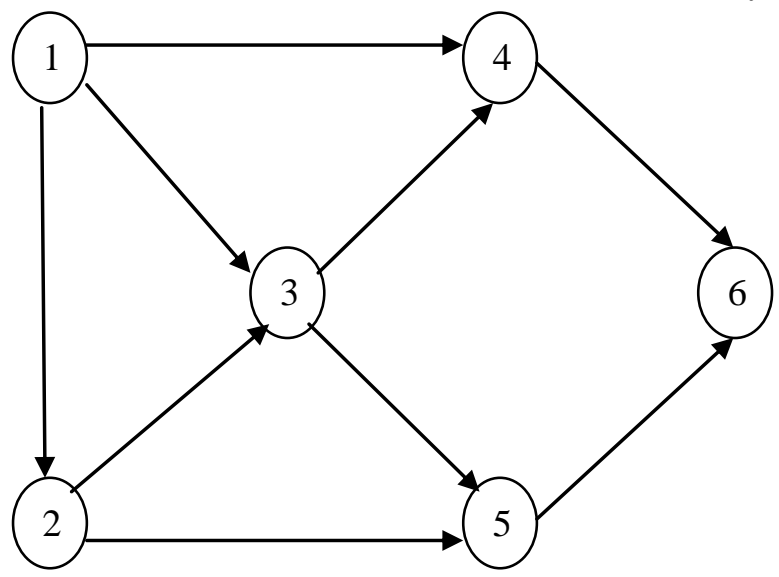

Figure.5.1. Network Project

\subsection{Fuzzy Activity Time for Trapezoidal and Triangular FuzzyNumbers}

The venture given in Fig.(2) fuzzy action times are spoken to by trapezoidal and triangular fuzzy numbers.

Table 1: Total float value

\begin{tabular}{|c|c|c|c|c|}
\hline Activity & $\begin{array}{c}\text { ActivityTime in } \\
\text { Trapezoidal }\end{array}$ & Total float & $\begin{array}{c}\text { ActivityTime in } \\
\text { Triangular }\end{array}$ & Total float \\
\hline $1-2$ & $(3,5,6,9)$ & $(-24,-4,4,24)$ & $(3,6,9)$ & $(-24,0,24)$ \\
\hline $1-3$ & $(6,8,9,12)$ & $(-18,0,7,25)$ & $(6,9,12)$ & $(-18,4,25)$ \\
\hline $1-4$ & $(8,10,11,14)$ & $(-4,11,17,32)$ & $(8,11,14)$ & $(-4,15,32)$ \\
\hline $2-3$ & $(4,6,7,9)$ & $(-24,-4,4,24)$ & $(4,7,9)$ & $(-24,0,24)$ \\
\hline $2-5$ & $(4,7,7,10)$ & $(-8,10,16,35)$ & $(4,7,10)$ & $(-8,14,35)$ \\
\hline $3-4$ & $(9,12,13,16)$ & $(-24,-4,4,24)$ & $(9,13,16)$ & $(-24,0,24)$ \\
\hline $3-5$ & $(10,13,14,17)$ & $(-24,-4,4,25)$ & $(10,14,17)$ & $(-24,0,25)$ \\
\hline $4-6$ & $(14,16,17,20)$ & $(-24,-4,4,24)$ & $(14,17,20)$ & $(-24,0,24)$ \\
\hline $5-6$ & $(12,15,16,19)$ & $(-24,-4,4,25)$ & $(12,16,19)$ & $(-24,0,25)$ \\
\hline
\end{tabular}

These are the paths from the Fig.(2) 1-4-6, 1-2-5-6, 1-3-4-6, 1-2-3-5-6, 1-3-5- 6 and 1-2-3-4-6. 


\section{Defuzzification Formula for Modelling and Scheduling A Furniture Fuzzy Project Network}

\subsection{Centroid Method for Triangular FuzzyNumber}

Fuzzy activity and slack time for each path is given below. And defuzzified values are calculated using triangular centroid formula.

$$
\text { Centroid }(A)=\frac{a+b+c}{3}
$$

Table 2: Defuzzified values of each path

\begin{tabular}{|c|c|c|c|}
\hline Path & FuzzyActivityTime & $\begin{array}{c}\text { SlackTime } \\
(\mathrm{a}, \mathrm{b}, \mathrm{c})\end{array}$ & $\begin{array}{c}\text { DefuzzifiedValue } \\
\text { using eqn.(2) }\end{array}$ \\
\hline $1-4-6$ & $(22,28,34)$ & $(-28,15,56)$ & 14.333 \\
\hline $1-2-5-6$ & $(19,29,38)$ & $(-56,14,83)$ & 13.666 \\
\hline $1-3-4-6$ & $(29,39,48)$ & $(-66,4,73)$ & 3.666 \\
\hline $1-2-3-5-6$ & $(29,43,54)$ & $(-96,0,97)$ & 0.666 \\
\hline $1-3-5-6$ & $(28,39,48)$ & $(-66,4,74)$ & 4 \\
\hline $1-2-3-4-6$ & $(30,43,54)$ & $(-96,0,96)$ & 0 \\
\hline
\end{tabular}

We used defuzzified formula and we are getting the minimum value is 0 . The path 1-2-3-4-6 is the critical path for the network. This is the critical path for the considered fuzzy project network.

\subsection{Centroid Method for Trapezoidal FuzzyNumbers}

Fuzzy activity and slack time for each path given below. And defuzzified values are calculated using trapezoidal centroid formula.

$$
\operatorname{Centroid}(A)=\frac{\left(c^{2}+d^{2}+c d\right)-\left(a^{2}+b^{2}+a b\right)}{3[(c+d)-(b+a)]}(3)
$$

Table 3: Defuzzified values of each path

\begin{tabular}{|c|c|c|c|c|}
\hline Path & $\begin{array}{c}\text { FuzzyActivity } \\
\text { time }\end{array}$ & $\begin{array}{c}\text { SlackTime } \\
(\mathrm{a}, \mathrm{b}, \mathrm{c}, \mathrm{d})\end{array}$ & $\frac{a+b+c+d}{4}$ & Values using eqn.(3) \\
\hline $1-4-6$ & $(22,26,28,34)$ & $(-28,7,21,56)$ & 14 & 14 \\
\hline $1-2-5-6$ & $(19,27,29,38)$ & $(-56,2,24,84)$ & 13.5 & 13.625 \\
\hline $1-3-4-6$ & $(29,36,39,48)$ & $(-66,-8,15,73)$ & 3.5 & 3.5 \\
\hline $1-2-3-5-6$ & $(29,39,43,54)$ & $(-96,-16,16,98)$ & 0.5 & 0.619 \\
\hline $1-3-5-6$ & $(28,36,39,48)$ & $(-66,-8,15,74)$ & 3.75 & 3.809 \\
\hline $1-2-3-4-6$ & $(30,39,43,54)$ & $(-96,-16,16,96$ & 0 & 0 \\
\hline
\end{tabular}

We used defuzzified formulae and we are getting the minimum value is 0 . This is the critical path 1-2-3-4-6for the furniture network.

Table 4: Total float of each activity

\begin{tabular}{|c|c|c|}
\hline Activities & FuzzyAactivity time & Total float \\
\hline $1-2$ & $(3,3,4,5,6,7,8,9)$ & $(-24,-18,-11,-4,4,11,18,24)$ \\
\hline $1-3$ & $(6,7,8,8,9,10,11,12)$ & $(-18,-13,-6,0,7,12,18,25)$ \\
\hline $1-4$ & $(8,9,10,10,11,12,13,14)$ & $(-4,0,6,11,17,21,26,32)$ \\
\hline $2-3$ & $(4,4,5,6,7,8,8,9)$ & $(-24,-18,-11,-4,4,11,18,24)$ \\
\hline $2-5$ & $(4,5,6,7,7,8,9,10)$ & $(-8,-3,4,10,16,23,29,35)$ \\
\hline $3-5$ & $(10,11,12,13,14,15,16,17)$ & $(-24,-18,-11,-4,4,11,18,25)$ \\
\hline $3-4$ & $(9,10,11,12,13,14,15,16)$ & $(-24,-18,-11,-4,4,11,18,24)$ \\
\hline $4-6$ & $(14,15,16,16,17,18,19,20)$ & $(-24,-18,-11,-4,4,11,18,24)$ \\
\hline $5-6$ & $(12,13,14,15,16,17,18,19)$ & $(-24,-18,-11,-4,4,11,18,25)$ \\
\hline
\end{tabular}

The possible paths for the project network and fuzzy slack times are calculated and given below 


\subsection{Proposed Centroid method using Octagonal FuzzyNumbers}

The project network given in Fig.(2) octagonal fuzzy numbers are used to represent the activity times

Table 5: Defuzzified values of each path

\begin{tabular}{|c|c|c|c|}
\hline Path & $\begin{array}{c}\text { Slack time } \\
(\mathrm{a}, \mathrm{b}, \mathrm{c}, \mathrm{d})\end{array}$ & $\frac{a+b+c+d+e+f+g+h}{8}$ & $\begin{array}{c}\text { Proposed } \\
\text { Defuzzified Value } \\
\text { using eqn. (1) }\end{array}$ \\
\hline $1-4-6$ & $(-28,-18,-5,7,21,32,44,56)$ & 13.625 & 12.374 \\
\hline $1-2-5-6$ & $(-56,-39,-18,2,24,46,66,84)$ & 13.625 & 12.523 \\
\hline $1-3-4-6$ & $(-66,-49,-28,-8,15,34,54,73)$ & 3.125 & 2.219 \\
\hline $1-2-3-5-6$ & $(-96,-72,-44,-16,16,46,74,98)$ & 0.75 & 0.184 \\
\hline $1-3-5-6$ & $(-66,-49,-28,-8,15,35,55,74)$ & 3.5 & 3.031 \\
\hline $1-2-3-4-6$ & $(-96,-72,-44,-16,16,44,72,96)$ & 0 & 0 \\
\hline
\end{tabular}

We used defuzzified formulae and we are getting the minimum value is 0 . This is the critical path 1-2-3-4-6for the furniture network.

\subsection{Comparison of the proposed method with the existingmethods}

Here triangular, trapezoidal and octagonal fuzzy numbers are compared. For finding the critical path in the project network octagonal fuzzy number is the better method.

Table 6.Comparison of fuzzy numbers

\begin{tabular}{|c|c|c|c|}
\hline Path & $\begin{array}{c}\text { Triangular } \\
\text { FuzzyNumber }\end{array}$ & $\begin{array}{c}\text { Trapezoidal } \\
\text { FuzzyNumber }\end{array}$ & $\begin{array}{c}\text { ProposedOctagonal } \\
\text { Number }\end{array}$ \\
\hline $1-4-6$ & 14.333 & 14 & 12.374 \\
\hline $1-2-5-6$ & 13.666 & 13.625 & 12.523 \\
\hline $1-3-4-6$ & 3.666 & 3.5 & 2.219 \\
\hline $1-2-3-5-6$ & 0.666 & 0.619 & 0.184 \\
\hline $1-3-5-6$ & 4 & 3.809 & 3.031 \\
\hline $1-2-3-4-6$ & 0 & 0 & 0 \\
\hline
\end{tabular}

\section{VI.CONCLUSION}

This research article we have presented a proposed centroid method for fuzzy project network to find the critical path using octagonal fuzzy numbers. We have computed numerical example to compare with the existing methods and the illustrated method. This method will enable to meet the complex fuzzy project time line by channelizing resource on the Critical Path activities.

\section{REFERENCES}

1. Gin-Shuh Liang and Tzeu-Chen Han.(2004).Fuzzy Critical Path for Project Network, Information and Management Sciences, Vol.15, No. 4,29-40.

2. Gunadi, Nurcahyo, W., SitiMariyamShamsuddin, Rose Alinda Alias and Mohd. Noor Md. Sap.(2003). Selection of Defuzzification Method to Obtain Crisp Value for Representing Uncertain Data in a Modified Sweep Algorithm", JCS\&T, Vol.3, No. 2, 22- 28.

3. M. Hapke, R. Slowinski. (1996).Fuzzy priority heuristics for project scheduling, Fuzzy sets and systems, Vol. 83, No.3,291299.

4. R. Jain. (1978). A procedure for multi-aspect decision making using fuzzy sets, Internat.J. Systems, Sci. Vol.8, 1- 7 .

5. J.E. Kelley. (1961). Critical path planning and scheduling Mathematical basis, Oper. Res.Vol. 9,296-320.
6. Lazim Abdullah and NorJamalina Jamal. (2010). CentroidPoint of Ranking Fuzzy Numbers and Its Application to Health Related Quality of Life Indicators, International Journal on Computer Science and Engineering, Vol.2, No.8,27732777.

7. MalekMasmoudi and Alain Hait. (2011). Fuzzy capacity planning for an helicopter maintenance center, International Conference on Industrial Engineering and Systems ManagementIESM',1-10.

8. Prade, H. (1979). Using fuzzy sets theory in a scheduling problem: a case study, Fuzzy Sets and Systems, No.2,153165.

9. Ravi Shankar, N., Sireesha, V.andPhaniBushanRao, P. (2010). An Analytical Method for Finding Critical Path in a Fuzzy Project Network, Int. J. Contemp. Math. Sciences, Vol. 5, No. 20, $953-962$.

10. Shahsavari Pour, N., Zeynali, S. and Pour Kheradmand, M. (2012). Calculating the Fuzzy Project Network Critical Path. International Journal of Engineering and Technology, Vol.1, No.2,58-66.

11. Taha, A. (2010).Operations Research: An Introduction. N.-Y.: Prentice Hall, 790p.

12. Zadeh, L.A. (1978). Fuzzy sets as a basis for a theory of possibility. Fuzzy sets and systems,3-28. 